\title{
Continuous vs Intermittent Phototherapy in the Management of Non-Haemolytic Neonatal Hyperbilirubinemia - A Randomised Non - Inferiority Study
}

\section{Mallanagouda M Patil, Gowthami G S, Hidaytullah R Bijapure, Anil Kumar Sajjan, S S Kalyanshettar and S V Patil}

Department of Paediatrics, Bijapur Lingayat District Educational Association (Deemed To Be University), Vijayapur, India

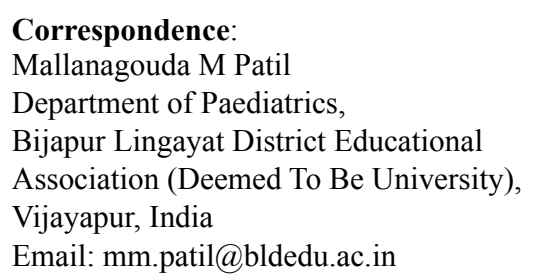

DOI: $10.3126 /$ jnps.v40i3.29535

Submitted on: 2020-06-19

Accepted on: 2020-10-04

Acknowledgements: None

Funding: Nil

Conflict of Interest: None declared

Permission from IRB: Yes

To cite this article: Patil MM, Gowthami GS, Bijapure HR, Sajjan AK. Continuous Vs Intermittent Phototherapy In The Management Of Non-Hemolytic Neonatal Hyperbilirubinemia - A Randomized Non - Inferiority Study. J Nepal Paediatr Soc. 2020;40(3):185-9

\begin{abstract}
Introduction: Phototherapy is used to manage neonatal hyperbilirubinemia in early life. We aimed to compare between intermittent and continuous phototherapy in reducing TSB, rate of fall of bilirubin, duration of phototherapy and duration of hospitalisation in neonates with non-haemolytic hyperbilirubinemia.

Methods: Total 190 neonates who were $>34$ weeks and birth weight $\geq 2000 \mathrm{gm}$ were included. They were randomised into group A (continuous phototherapy) and group B (intermittent phototherapy). Group A received phototherapy for three hours and 45 minutes off and group B received phototherapy for three hours and then three hours off. TSB levels estimation were done in both groups and compared after each 12 hours, 24 hours, and 48 hours of commencing phototherapy.
\end{abstract}

Results: The mean TSB at presentation was $15.64 \pm 2.19 \mathrm{mg} / \mathrm{dl}$ for continuous and $15.03 \pm 1.07 \mathrm{mg} / \mathrm{dl}$ for intermittent group. Mean TSB at $12,24,48$ hours were $13.26 \pm 2.4 \mathrm{mg} / \mathrm{dl}, 10.8 \pm 1.72 \mathrm{mg} / \mathrm{dl}, 10.16$ $\pm 0.95 \mathrm{mg} / \mathrm{dl}$ respectively for continuous and $12.6 \pm 1.65 \mathrm{mg} / \mathrm{dl}$, $10.04 \pm 1.8 \mathrm{mg} / \mathrm{dl}, 9.1 \pm 0.66 \mathrm{mg} / \mathrm{dl}$ respectively for intermittent group $(\mathrm{p}<0.05)$. The mean rate of fall in serum bilirubin was $0.22 \pm$ $0.12 \mathrm{mg} / \mathrm{dl} / \mathrm{hr}$ for group A and $0.21 \pm 0.08 \mathrm{mg} / \mathrm{dl} / \mathrm{hr}$ for group B (p = 0.45 ). There was not much difference in mean duration of hospitalisation in both groups $(\mathrm{p}=0.547)$.

Conclusions: Intermittent phototherapy is a non-inferior option to continuous phototherapy, in the management of non-haemolytic hyperbilirubinemia with additional advantages of less interrupted mother infant bonding and decreased irradiance.

Keywords: Continuous phototherapy; Intermittent phototherapy; Neonatal hyperbilirubinemia; Total Serum Bilirubin

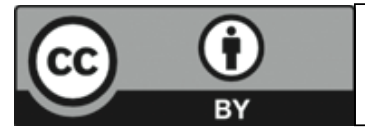

This work is licensed under creative common attribution 3.0 license 


\section{INTRODUCTION}

Phototherapy has become the main mode of therapy and prophylaxis of neonatal unconjugated hyperbilirubinemia. Phototherapy helps to reduce the rise of serum bilirubin concentration, regardless of maturity, presence or absence of haemolysis, or degree of skin pigmentation. ${ }^{1}$ About $97 \%$ of full term and preterm neonates demonstrate a biochemical hyperbilirubinemia (serum bilirubin $>$ $1 \mathrm{mg} / \mathrm{dl}$ ) and about $65 \%$ appear clinically jaundiced. ${ }^{2}$ It is the commonest cause of readmission during early neonatal period. American Academy of Paediatrics recommends that neonates discharged within 48 hours should have a follow-up visit after 48 to 72 hours for any significant jaundice and other problems. ${ }^{3}$

Phototherapy acts by photoisomerisation, which reduces the level of bilirubin by degradation of bilirubin. Photoisomerisation of bilirubin occurs primarily in skin layers and the restoration of the bilirubin pool in the skin takes approximately one to three hours. Thus a prolonged on and off schedule may not be as effective as continuous therapy, but an on-off cycle of less than one hour is apparently as effective as continuous treatment. ${ }^{4}$ The efficiency of phototherapy is related to the starting bilirubin concentration and efficiency will fall as the level of serum bilirubin decreases. It seems one to three hours period of phototherapy discounting would favour a more intense bilirubin rebound into the skin and theoretically increases the effect of phototherapy. One to three hours of phototherapy discounting would make time for nursing care of the baby, feeding, kangaroo mother care, building mother and infant bonding, saves time and work load on nurses and also reduces the cost of phototherapy. ${ }^{5}$

Hence the present study is intended to compare between continuous and intermittent phototherapy in terms of rate of fall of bilirubin, decrease in total serum bilirubin, duration of phototherapy and hospitalisation which will be helpful in the management of hyperbilirubinemia and also in providing day care to the neonate.

\section{METHODS}

This randomised interventional study was carried out on 190 neonates admitted in NICU of a tertiary care hospital in North Karnataka, India from November 2017 to April 2019. The study was performed after getting approval from the institutional ethics committee. Neonates $>34$ weeks, of both genders, delivered by both normal vaginal delivery and lower segment caesareansection, birth weight $\geq 2500$ gm and APGAR score $>7 / 10$ at one min were included in the study. The neonates with $\mathrm{Rh}$ incompatibility, $\mathrm{ABO}$ incompatibility, neonatal sepsis, congenital malformation, preterms, low birth weights were excluded.

The neonates on admission were randomised into two groups during admission-Continuous phototherapy (CPT) Group A and Intermittent phototherapy (IPT) Group B. Randomisation was done using block randomisation (block size 10) in which 190 subjects were equally grouped. Demographic details like age, sex, date and time of birth, mode of delivery, APGAR scores, mother and baby blood group and serum bilirubin levels were recorded. CPT (group A) received phototherapy for three hours and 45 min off. IPT (Group B) received phototherapy for three hours and then three hours off. During the off period baby was given to the mother for feeding, nursing as well as KMC care. Total serum bilirubin level estimation was done by peripheral venous sample by using VITROS BuBc Slide method on admission i.e. 0 hour. Phototherapy was initiated as per American Academy of Paediatrics 2004 guidelines. ${ }^{6}$ Total serum bilirubin levels in both A and B group were compared after each 12 hours, 24 hours, and 48 hours of commencing phototherapy. In both the groups, phototherapy was given using a double surface phototherapy unit (Phoenix brilliance classic with 12 LED bulbs, LED intensity $>45$ microwatt $/ \mathrm{cm}^{2} / \mathrm{nm}$, wavelength $450-465 \mathrm{~nm}$ ). A distance of 30 to $35 \mathrm{~cm}$ was maintained between the baby and bulb surface.

All statistical analyses were conducted by using Statistical Package for the Social Sciences (SPSS V. 17.0). The categorical variables were expressed in terms of percentages and Chi-square test was used 
Table 1. Baseline Characteristics

\begin{tabular}{lrr} 
Variables & \multicolumn{1}{c}{$\begin{array}{c}\text { CPT } \\
(\mathbf{n = 9 2 )}\end{array}$} & $\begin{array}{c}\text { IPT } \\
(\mathbf{n = 9 8 )}\end{array}$ \\
\hline \# Gestational age (w) & 39 & 39 \\
Males & $56(61.5)$ & $52(53.1)$ \\
\# APGAR & 7 & 77 \\
\# Age at diagnosis & 76 & 2740 \\
(hours) & & \\
\# Weight (g) & 2580 & \\
\# TSB at admission & $15.64 \pm 2.19$ & $15.03 \pm 1.07$ \\
(mg/dl) & & \\
$\begin{array}{l}\text { Values } \text { in } n \text { (\%) except \# Mean (SD) } \\
\text { CPT }- \text { Continuous phototherapy } \\
\text { IPT }- \text { Intermittent phototherapy }\end{array}$ & \\
\end{tabular}

for the analysis of these variables. Continuous variables with normal distribution were analysed by measures such as sample mean, standard deviation. Statistical significance was tested by Student's t test and non-parametric data by Mann-Whitney U test. Correlation among the biochemical parameters was analysed by Karl Pearson's Correlation Analysis. (p value of $<0.05$ was considered as significant).

\section{RESULTS}

Among 190 neonates, the baseline characteristics were comparable among the two groups. The mean age on admission was 76 hours and 77 hours in CPT and IPT groups respectively. There was no difference in mean gestational age and APGAR scores in both the groups. Mean weight of neonates on admission was 2580 grams and 2700 grams in CPT and IPT group respectively (Table 1).

The mean total serum bilirubin reduction at 12, 24 and 48 hours was significant in both the groups ( $p$ $<0.05$ ) (Table 2). However, the rate of fall of bilirubin in CPT and IPT was $0.22 \mathrm{mg} / \mathrm{dl} / \mathrm{hr}$ and $0.21 \mathrm{mg} / \mathrm{dl} / \mathrm{hr}$ respectively but this difference between the two groups was not statistically significant. In comparison to continuous phototherapy, the duration of phototherapy was less in intermittent phototherapy i.e. 27 hours and 18 hours. However, the difference was not statistically significant. Similarly, there was not much difference in the mean duration of hospitalisation in both groups (36 hours in CPT and 32.5 hour in
Table 2. Comparison of Mean TSB at 0, 12, 24 And 48 Hours Of Phototherapy In Both Groups

\begin{tabular}{|c|c|c|c|c|}
\hline $\begin{array}{l}\text { Time in } \\
\text { hours }\end{array}$ & $\begin{array}{c}\text { CPT } \\
\text { TSB (mg/ } \\
\text { dl) Mean } \\
\pm \text { SD (No. } \\
\text { of cases) }\end{array}$ & $\begin{array}{c}\text { IPT } \\
\text { TSB (mg/ } \\
\text { dl) Mean } \\
\pm \text { SD (No. } \\
\text { of cases) }\end{array}$ & $\begin{array}{c}\text { t } \\
\text { value }\end{array}$ & $\underset{\text { value }}{\mathbf{p}}$ \\
\hline $\begin{array}{l}\text { At } \\
\text { admission }\end{array}$ & $\begin{array}{l}15.64 \pm \\
2.19(92)\end{array}$ & $\begin{array}{l}15.03 \pm \\
1.07(98)\end{array}$ & 2.13 & $0.034 *$ \\
\hline $12 \mathrm{hrs}$ & $\begin{array}{l}13.26 \pm \\
2.4(91)\end{array}$ & $\begin{array}{l}12.6 \pm 1.65 \\
(98)\end{array}$ & 2.4 & $0.034 *$ \\
\hline $24 \mathrm{hrs}$ & $\begin{array}{l}10.8 \pm \\
1.72(71)\end{array}$ & $\begin{array}{l}10.04 \pm 1.8 \\
(83)\end{array}$ & 2.79 & $0.006^{*}$ \\
\hline $48 \mathrm{hrs}$ & $\begin{array}{l}10.16 \pm \\
0.95(21)\end{array}$ & $\begin{array}{l}9.1 \pm 0.66 \\
(11)\end{array}$ & 3.3 & $0.002 *$ \\
\hline
\end{tabular}

CPT-Continuous Phototherapy

IPT-Intermittent Phototherapy

TSB -Total serum bilirubin

$t$ - significance of difference

IPT). Cost involved in providing CPT was Rs 3400 which was comparatively higher than the price of IPT i.e. Rs 3000.

\section{DISCUSSION}

The difference between the mean baseline bilirubin, mean follow-up bilirubin at 12, 24 and 48 hours for both the groups CPT and IPT was statistically significant $(\mathrm{p}<0.05)$ (Table 2$)$. In a study by Niknafset et al. ${ }^{7}$, there was statistically no significant difference in the mean follow-up serum bilirubin in CPT and IPT groups. This difference could have resulted probably due to different definitions used for duration for phototherapy in both intermittent and continuous groups. The duration defined for "on and off phototherapy" (Three hours on, 45 minutes off for continuous group, three hours on, three hours off for intermittent group) in our study, might have decreased enterohepatic circulation of bilirubin (by allowing more time for feeding in intermittent group), resulting in significant fall in serum bilirubin compared to study by Niknafs et al. ${ }^{7}$ wherein they have used 'two hours on, half an hour off' in continuous group and 'one hour off, one hour on' in intermittent group. The duration of phototherapy was less in intermittent phototherapy group compared to continuous phototherapy group, 
which is similar to the results found in a study conducted by Monica et al. ${ }^{5}$

Previous studies comparing intermittent versus continuous phototherapy have produced conflicting results. As exposure to light increases excretion of bilirubin, continuous phototherapy would be more effective than intermittent one. Lau and Fung ${ }^{8}$ showed that the difference in serum bilirubin kinetics between continuous and intermittent phototherapy was insignificant and a schedule of one in four hours of irradiation achieved the same treatment effect as continuous phototherapy. In our study we observed duration of phototherapy was significantly higher in CPT when compared to IPT groups. Our finding is similar to previous studies published by Maurer and $\operatorname{Vog} 1^{9,10}$ who showed that intermittent phototherapy did not cause longer phototherapy duration. This could have been resulted due to the fact that photoisomerisation occurs within minutes and bilirubin slowly migrates to the skin over hours. As photoisomerisation occurs primarily in the skin layers and the restoration of the bilirubin pool in the skin takes approximately one to three hours, theoretically, intermittent phototherapy regimens should be equally effective. Following this hypothesis, many researchers tried to study the efficacy of IPT. However, a prolonged on-off schedule may not be as effective as continuous therapy, but an on - off cycle of less than one hour should be apparently as effective as continuous therapy. ${ }^{7}$

The concept of IPT is definitely more attractive than CPT one. Besides its simplicity in practice, it is also economically attractive for developing countries where the need is more and resources are limited. Moreover, this regimen is less interruptive to the establishment of mother infant bonding and breast feeding, as the neonates are not restricted to the phototherapy unit during the entire course of phototherapy management. This regimen allows mothers to involve in the nursing care (like cleaning, feeding, changing diapers) of their babies. This is important, especially in resource limited countries, as the burden of neonatal care is shared between the mothers and nursing staffs. It also reduces stress and anxiety in mothers, as they spend more time (phototherapy off time) with their babies.

We tried to compare the efficacy between IPT and CPT in our centre. However, our findings may not be generalised to the entire population in view of being a single centric study. Hence, further research is warranted in this area where multi centric and larger number of babies could be studied simultaneously. This could have a long term implication, especially in resource-limited set up like ours.

\section{CONCLUSIONS}

Intermittent phototherapy is a non-inferior option to continuous phototherapy, in the management of non-hemolytic hyperbilirubinemia with additional advantages of less interrupted mother infant bonding thereby promoting exclusive breast feeding, less workload on nurses as mothers are involved in care of the baby and decreased irradiance.

\section{REFERENCES}

1. Suri D, Krithika AP, Somasekar R. A comparative study to determine intermittent versus continuous phototherapy for reducing neonatal hyperbilirubinemia at tertiary care hospital in Chennai, Tamil Nadu, India. Int J Contemp Pediatr. 2019;6(6):2287-91. DOI: http://dx.doi.org/10.18203/2349-3291.ijcp20194536

2. Onyango AB, Suresh G, Were F. Intermittent phototherapy versus continuous phototherapy for neonatal jaundice. Cochrane Database Syst. Rev. 2009(4). DOI: https://doi.org/10.1002/14651858.CD008168

3. Reshad M, Ravichander B, Raghuraman TS. A study of cord blood albumin as a predictor of significant neonatal hyperbilirubinemia in term and preterm neonates. Int J Res Med Sci. 2016;4(887):e90. DOI: http://dx.doi.org/ 10.18203/2320-6012.ijrms20160537 
4. Ip S, Chung M, Kulig J. An evidence-based review of important issues concerning neonatal hyperbilirubinemia. Pediatrics. 2004;114(1):130-153.PMID: 15231986

5. Sachdeva M, Murki S, Oleti TP, Kandraju H. Intermittent versus continuous phototherapy for the treatment of neonatal non-hemolytic moderate hyperbilirubinemia in infants more than 34 weeks of gestational age: a randomized controlled trial. Eur J Pediatr. 2015;174(2):177-81. DOI:10.1007/s00431-014-2373-8

6. Subcommittee on Hyperbilirubinemia. Management of Hyperbilirubinemia in the Newborn Infant 35 or More Weeks of Gestation. Pediatrics. 2004;114(1): 297-316. DOI: https://doi.org/10.1542/peds.114.1.297

7. Niknafs P, Mortazavi AA, Torabinejad MH, Bijari BB, Niknafs N. Intermittent Versus Continuous Phototherapy for Reducing Neonatal Hyperbilirubinemia. Iran J Pediatr. 2008;18:251-6.

8. Lau SP, Fung KP. Serum bilirubin kinetics in intermittent phototherapy of physiological jaundice. Arch Dis Child. 1984;59(9):892-4. DOI:10.1136/adc.59.9.892

9. Maurer HM, Shumway CN, Draper DA, Hossaini AA. Controlled trial comparing agar, intermittent phototherapy, and continuous phototherapy for reducing neonatal hyperbilirubinemia. J Pediatr. 1973;82(1):73-6. DOI:10.1016/ s0022-3476(73)80014-9

10. Vogl TP, Hegyi T, Hiatt IM, Polin RA, Indyk L. Intermediate phototherapy in the treatment of jaundice in the premature infant. J Pediatr. 1978;92(4):627-30. DOI:10.1016/s0022-3476(78)80308-4. 